number of serious road traffic injuries: 1) by applying correction factors on police data, 2) by using hospital data and 3) by using linkage between police and hospital data. Quality of data and method differ between Member States. The impact of this heterogeneity on final estimations is unknown. We aim to analyse the impact of a) the criteria used to select hospital casualties, b) on the converter to derive MAIS, and c) on the method used on the reliability of the estimation and the comparability across countries.

Methods Three sub-studies will be carried out:

a. A cross-sectional study of Hospital Discharge Data. This study will define criteria for inclusion/exclusion based on codes of the classification of diseases/injuries used (ICD9, ICD10, and AIS).

b. A sensitivity analysis to assess the impact of obtaining MAIS from different methods (codifying directly with AIS, or converting from ICD diagnosis with Icdpic (stata), ICDMAP90, ECIP-Apollo, or EU-AAAM).

c. Comparison of the three methods to estimate number of serious injured.

Results The future results will help to report serious road traffic injuries by EU Member States with standard criteria that would allow comparisons.

Conclusions It is expected to provide specific guidelines for reporting serious road traffic injuries and to allow comparability between countries.

\section{IMPROVING ROAD SAFETY IN THE BALTIC STATES- ROLE OF STRATEGIES}

${ }^{1}$ Dago Antov, ${ }^{2} J u r i s$ Smirnovs. ${ }^{1}$ Tallinn University of Technology, Estonia; ${ }^{2}$ Riga Technical University, Latvia

\subsection{6/injuryprev-2016-042156.78}

Background In the beginning of 90's the Baltic states' road safety fatality records were among the worst in Europe. After that period, the situation has been improved essentially, but despite of that the Baltic states still remain not the safest countries in Europe. An important role here played the road safety strategies, first developed already in 1990's. This paper analysis the safety situation developments in the Baltic states as well the role of road safety strategies, which have been slightly different in three countries.

Methods Statistical analysis on road safety data gives us a rather clear picture about the safety situation in three Baltic states- Lithuania, Latvia and Estonia. The background data hereby has been included, in order to explain the transportation situation and it's impacts on safety. The content analysis of the strategies shows the similarities and differences of the strategies introduced in different countries, as well as the impact on the safety records.

Results The results of this research shows clearly that in spite of the different strategic approach towards the road safety, the basic trends of the road safety in three Baltic states have big similarities. It proves that even the measures introduced in three Baltic states and written in strategies are different ones, the basic safety trends are influenced not only by the strategies, but also by the social impact, like motorization or spatial planning.

Conclusions The role of road safety strategies have been important in order to evaluate the safety situation as well as to rank the countries with other countries. The numeric goals, included in the strategies are important in order to follow the main safety trends. But in spite of that, some general impact factors have been estimated to be as important as strategies. Here the main important could be listed - motorization, road network data, population, road user attitudes, etc.

\section{THE CRIMINAL LAW AND UNAUTHORISED AND MALICIOUS INTERFERENCE WITH AUTOMATED AND CONNECTED CARS}

${ }^{1}$ Mark Brady, ${ }^{1}$ Kieran Tranter, ${ }^{2}$ Andry Rakotonirainy. 'Socio-Legal Research Centre and Griffith Transport - Griffith University, Australia; ${ }^{2}$ Centre for Accident Research Road Safety - CARRS-Q - Queensland University of Technology - Australia

10.1136/injuryprev-2016-042156.79

Background Driverless cars are no longer a science fiction and is clearly looming in the transport horizon. Software and wireless networks are increasingly controlling all aspects of transport's landscape. Advances in technology have outpaced research in human factors and policy therefore serious questions must be asked about the legal protections of the integrity of these new systems to guarantee community's safety. Furthermore the research knowledge to understand and define the key safety issues that the community required to advance a policy action plan is still in its infancy. Specifically we do not know how effective are the deterrence and penalties within Australia's criminal law in respect to the unauthorised and malicious interference with in-vehicle computer systems?

Method We discuss existing and near-future scenarios where there might be unauthorised and malicious interference with invehicle computer systems. Examples range from a malcontent hacking a vehicle's system to cause it to crash, to a third-party installing spyware on a vehicle to gather private data about the vehicle's movements. We then articulate the range of criminal provisions, at a state and federal level that cover the unauthorised and malicious interference with in-vehicle computer systems. The lack of detailed case law (reflecting a very low level of prosecutions) suggests that overarching difficulties might lie with the forensics of investigation and known problems with the policing of cybercrimes.

Results We show how Australian criminal law could cover future scenarios. We demonstrate a lack of case law suggesting that overarching difficulties might lie with the forensics of investigation and known problems with the policing of cybercrimes.

Conclusion This paper will help policy makers to build up a clear understanding of the adequacies of Australian state and federal criminal law successfully support transitioning into future of cooperative and autonomous transport systems.

\section{DEVELOPING THE EUROPEAN ROAD SAFETY DECISION SUPPORT SYSTEM}

${ }^{1}$ George Yannis, ${ }^{2}$ Pete Thomas, ${ }^{1}$ Eleonora Papadimitriou, ${ }^{2}$ Rachel Talbot, ${ }^{3}$ Heike Martensen. ${ }^{1}$ National Technical University of Athens; ${ }^{2}$ Loughborough; ${ }^{3}$ Belgian Institute for Road Safety

\subsection{6/injuryprev-2016-042156.80}

Background The European Road Safety Decision Support System (DSS) is one of the key objectives of the European co-funded research project SafetyCube in order to better support evidencebased policy making. The SafetyCube project results will be assembled in the form of a Decision Support System that will present for each suggested road safety measure: details of the risk factor tackled, the measure itself, the best estimate of casualty 